\title{
Short term UV-B radiation mediated modulation of physiological traits and withanolides production in Withania coagulans $(\mathbf{L}$. Dunal under in-vitro condition
}

\author{
Deepika Tripathi $^{1} \cdot$ Ram Prasad Meena $^{1} \cdot$ Shashi Pandey-Rai $^{1}$ (D
}

Received: 4 March 2021/Revised: 30 July 2021 / Accepted: 3 August 2021/Published online: 11 August 2021

(c) Prof. H.S. Srivastava Foundation for Science and Society 2021

\begin{abstract}
Accumulation of secondary metabolites is a key process in the growth and development of plants under different biotic/abiotic constraints. Many studies highlighted the regulatory potential of UV-B treatment towards the secondary metabolism of plants. In the present study, we examined the impact of UV-B on the physiology and secondary metabolism of Withania coagulans, which is an important ayurvedic plant with high anti-diabetic potential. Results showed that in-vitro UV-B exposure negatively influenced chlorophyll content and photosynthetic machinery. However, Fv/Fm ratio was found non-significantly altered up to $3 \mathrm{~h}$ UV-B exposure. The maximum lipid peroxidation level was recorded with $46.8 \%$ higher malondialdehyde content in the plants supplemented with $5 \mathrm{~h}$ UV-B radiation, that was indicated the oxidative stress in W. coagulans. Conversely, UV-B treatment significantly increased the plant's stress protective compounds like carotenoids, anthocyanin, phenol and proline, in W. coagulans. Free radical scavenging activity was also significantly increased $\sim 18 \%$ than the control with $3 \mathrm{~h} \mathrm{UV-B}$ treatment. The maximum antioxidative enzymes activities were observed with the short-term (up to $3 \mathrm{~h}$ ) UV-B treatment. Specifically, UV-B radiation exposure significantly increased the content of withaferin A and withanolide A in W. coagulans with maximum 1.38 and 3.42-folds, respectively. Additionally, withanolides biosynthesis related genes transcript levels were found over-expressed under the response of UV-B elicitation. The acquired
\end{abstract}

Shashi Pandey-Rai

pshashi@bhu.ac.in; shashi.bhubotany@gmail.com

1 Laboratory of Morphogenesis, Department of Botany, Institute of Science, Banaras Hindu University (BHU), Varanasi 221005, Uttar Pradesh, India results suggested that short-term UV-B supplementation triggers secondary metabolism along with combating oxidative stress via improving the antioxidative defense system in W. coagulans. Also, UV-B can be used as an efficient abiotic elicitor to increase pharmaceutical compounds (withanolides) production.

Keywords UV-B radiation - Antidiabetic plant - In-vitro grown plantlets · Antioxidative defense system · Secondary metabolites $\cdot$ Abiotic elicitor

\section{Introduction}

The most important source of energy on the earth is sunlight, which is necessary for all the vital processes of living organisms. Ultraviolet (UV) radiation is one of the major components of the solar spectrum that can be reached on the earth's surface (Dotto et al. 2018). However, naturally, various lines of defense are available to overcome the reach/effect of hazardous natural radiations on biotic components such as geomagnetic field, stratospheric ozone layer etc. (Herndon et al. 2018). The stratospheric ozone layer is preventing approximately $90 \%$ of UV-B (290-320 $\mathrm{nm})$ and $100 \%$ of UV-C (100-290 $\mathrm{nm})$ radiation to reach on the earth surface. Although from the last two decades, stratospheric ozone layer depletion has come under the light due to severe accumulation of environmental pollutants that ultimately leads to penetration of UV-B rays on the earth surface (Barnes et al. 2019; Neale et al. 2021). Therefore, enhanced penetration of UV-B radiation has hiked the concern about their consequences on plants.

It has been now well proved that the impacts of UV-B exposure on plants are directly influenced by different 
factors like dose, fluence rate, wavelength, duration of UVB exposure etc. (Escobar-Bravo et al. 2019). Various studies have explained that based on these factors UV-B radiation caused impacts on plants system can be beneficial or deleterious (Schreiner et al. 2012; Parihar et al. 2015). Lots of studies have been reported that exposure of plants long term UV-B radiation can accelerates production of reactive oxygen species (ROS), damage of macromolecules and damage of photosynthetic machinery (Yokawa et al. 2016; Salama et al. 2011). While, low dose and short-term UV-B radiation can work as a regulatory environmental cue that modulates morphology, biochemistry and physiology of plants to ameliorate the UV-B toxicity and activate defensive strategies (Inostroza-Blancheteau et al. 2016; Yadav et al. 2020).

Various Studies reported that UV-B exposure induced photomorphogenic effects in plants via UV-photoreceptor that ultimately influences multiple physio-biochemical processes at vegetative and reproductive stages (Suchar and Robberecht 2015; Mariz-Ponte et al. 2018). Under UVB supplementation, loss of photosynthetic pigments, loss of integrity of thylakoid membrane, reduced Rubisco enzymatic activity, and down-regulation of the transcript level of photosynthesis related genes belongs to the main reasons responsible for physiological disorders that consequently suppress plant growth and development (Jansen et al. 1996; Hollosy 2002). To adapt against the hazardous responses of UV-B, plants develop a variety of regulatory mechanisms, like enhanced protective mechanisms and activated repair mechanisms (Inostroza-Blancheteau et al. 2016; Piccini et al. 2020). On UV-B exposure, enhanced or upregulated activities of antioxidative defense (enzymatic and non-enzymatic) systems in plants are known to cope up from the excess accumulation of ROS and lipid peroxidation (Jaiswal et al. 2020; Rai et al. 2011). Many studies have reported the induction of secondary metabolites biosynthesis under UV-B supplementation and suggesting its protective role against UV-B stress (Schreiner et al. 2012; Yadav et al. 2020). Terpenoids comprise a large group of secondary metabolites, that help to protect plant leaves from UV-B-induced rapid heating (Liu et al. 2017). As a response to UV-B exposure, the induction of terpenoids biosynthesis has been previously reported in various commercially / medicinally important plant species such as Vitis vinifera L., Cuminum cyminum L., Curcuma caesia Roxb., Artemisia апnиa L. etc. (Gil et al. 2012; Ghasemi et al. 2019; Jaiswal et al. 2020; Li et al. 2021).

Withania coagulans (L.) Dunal (family- Solanaceae) is an endangered medicinal plant that is grown in temperate and tropical regions of Asia. In Ayurveda, it is used for the treatment of a hyperglycemic conditions from very ancient times. Apart from this, it is also having great potential to work as a good antilipidemic, anti-cancerous, anti- microbial and immune suppressive agent (Tripathi et al. 2018). The major bioactive chemical constituents of this plant are withanolides which are chemically $\mathrm{C}_{28}$ triterpenoid steroidal lactone and responsible for its medicinal virtue. Recently, it has also been reported that withanolides can be potentially used to cure novel coronavirus (SARSCoV-2) as an immune booster and anti-viral agent (Maurya and Sharma 2020). Biosynthesis of withanolides takes place utilizing two different pathways, one is mevalonate pathway which is localized in cytosol and another is 2-Cmethyl-D-erythritol-4-phosphate (MEP) pathway localized in the plastid. The upstream part of both the pathways involves the process of isoprenogenesis, which later diverges into triterpene and sterol biosynthesis. Secondary metabolites biosynthetic pathways are often inducible by the exogenous addition of various biotic and abiotic elicitors (Bulchandani and Shekhawat 2020). Previously, biosynthesis of withanolides has been reported to be governed with different elicitors in W. somnifera and Physalis peruviana (Singh et al. 2015; Şahin 2019). Many studies have been carried out to improve the sustainability of $W$. coagulans in nature, but the study about the impact of abiotic elicitors (such as- drought, light, UV radiation etc.) on secondary metabolism of $W$. coagulans is still in the infancy stage which can enhance the medicinal efficiency of this plant with enhanced biosynthesis of withanolides. Therefore, in this study, we aim to understand the impact of short-term UV-B exposure as an abiotic elicitor on physiology, antioxidative defense system, and secondary metabolites production of W. coagulans under invitro conditions.

\section{Materials and methods}

\section{Plant material and UV-B exposure}

Shoot apical meristems (SAM, $1 \mathrm{~cm}$ ) of $W$. coagulans (as explants) were collected from Botanical Garden, Department of Botany, Banaras Hindu University (BHU), Varanasi- India, and established under in-vitro conditions according to Tripathi et al. 2018. In-vitro grown rooted plantlets were further acclimatized in sterilized soil and sand, $1: 1$ ratio at $25 \pm 2{ }^{\circ} \mathrm{C}$ temperature and $80-90 \%$ relative humidity (RH) (Fig. S1). One-month acclimatized plants (with 6-7 nodes) were taken for UV-B treatment. Invitro UV-B exposure was given in 6 sets of plants as control, $1 \mathrm{~h}, 2 \mathrm{~h}, 3 \mathrm{~h}, 4 \mathrm{~h}$, and $5 \mathrm{~h}$ treated plant sets, respectively. The UV-B $\left(2.8 \mathrm{~W} \mathrm{~m}^{-2}\right.$ dose $)$ exposure was given by G15T8E UV-B lamps (Sankyo Denki co., Ltd, Japan) as similar as Pandey and Pandey-Rai (2014a). 
Estimation of chlorophyll, carotenoids and anthocyanin

Photosynthetic pigments were measured in following Porra et al. (1989). For the estimation of photosynthetic pigments, fresh leaves $(0.3 \mathrm{~g})$ were homogenized with $10 \mathrm{ml}$ $80 \%(\mathrm{v} / \mathrm{v})$ acetone and centrifuged for $10 \mathrm{~min}$ at $12,000 \times \mathrm{g}$. The supernatant was taken to measure optical density at $663,645,480$, and $510 \mathrm{~nm}$. Anthocyanin was estimated by the procedure of Mancinelli et al. (1975). Fresh leaves $(100 \mathrm{mg})$ in acidified methanol $(1: 99, \mathrm{HCl}$ : methanol) were used for anthocyanin extraction. After $24 \mathrm{~h}$ extract incubation at $0 \mathrm{C}$, the final volume was made up to $10 \mathrm{ml}$ and absorbance was taken at $530 \mathrm{~nm}$ using a double beam spectrophotometer (Hitachi U-2910, Tokyo- Japan).

\section{Chlorophyll fluorescence and gas exchange measurements}

Chlorophyll fluorescence parameters were determined by using pulse amplitude modulation (PAM) -2500 portable chlorophyll fluorometer connected with data acquisition software Pam-Win3. Before the data estimation, a dark condition was provided to plants (control and UV-B exposed) for $20 \mathrm{~min}$. All the plant samples were treated to a low irradiance of light for the estimation of the minimal fluorescence (Fo) and a saturation pulse $\left(3,000 \mu \mathrm{mol} \mathrm{m}{ }^{-2} \mathrm{~s}^{-1}\right)$ for the maximum fluorescence (Fm) measurement. Maximal quantum yield $(\mathrm{Fv} / \mathrm{Fm})$ was calculated with the following formula:

$\mathrm{Fv} / \mathrm{Fm}=(\mathrm{Fm}-\mathrm{Fo}) / \mathrm{Fm}$.

Leaf gas exchange analysis was performed on intact leaves immediately after UV-B treatment. Gas exchange parameters such as photosynthetic rate, transpiration rate, stomatal conductance, and intercellular $\mathrm{CO}_{2}$ concentration were measured with the help of LICOR-6400XT portable photosynthetic system.

\section{Estimation of lipid peroxidation and free radical scavenging activity}

The oxidative stress level was recorded by calculating the content of malondialdehyde (MDA). The lipid peroxidation (LPO) level was calculated as the thiobarbituric acid (TBA) method. For the extraction, leaf samples $(200 \mathrm{mg})$ were first homogenized in $5 \mathrm{ml}$ of tri-chloroacetic acid (TCA, $10 \%$ ) containing $0.25 \%$ of TBA (Heath and Packer 1968). The reaction mixture containing plant extract was then heated at $90{ }^{\circ} \mathrm{C}$ for $30 \mathrm{~min}$. Followed by immediate cooling, the mixture was centrifuged at $8000 \mathrm{rpm}$ for $15 \mathrm{~min}$ and absorbance of the supernatant was measured at $532 \mathrm{~nm}$.
Free radical scavenging activity of $W$. coagulans plants (both control and UV-B exposed) was estimated by 2,2diphenyl picryl hydrazyl (DPPH) assay. Fresh leaves $(200 \mathrm{mg})$ were ground in $80 \%$ methanol $(2 \mathrm{ml})$ and shake for 2 days at $80 \mathrm{rpm}$ per min. After centrifugation $300 \mu \mathrm{l}$ of supernatant was taken to make the final volume of $3 \mathrm{ml}$ with methanol. Then $150 \mu \mathrm{l}$ of $0.1 \mathrm{mM}$ DPPH was added and after robust mixing samples were kept at normal room temperature for $15 \mathrm{~min}$. The absorbance of the reaction samples was taken at $517 \mathrm{~nm}$.

\section{Measurement of total phenol and proline}

Total phenol content was measured through the folinciocalteu assay (Imeh and Khokhar 2002). Fresh $200 \mathrm{mg}$ leaves were collected and heated with $10 \mathrm{ml}$ of $1.2 \mathrm{M} \mathrm{HCl}$ (prepared in $50 \%$ aqueous methanol) at $90^{\circ} \mathrm{C}$ for $2 \mathrm{~h}$. Then $20 \mu \mathrm{l}$ of the boiled sample (or standards) were added with $1.58 \mathrm{ml}$ distilled water and $100 \mu \mathrm{l}$ folin reagent. After $2 \mathrm{~min}, 1.9 \mathrm{M}$ sodium carbonate $\left(\mathrm{Na}_{2} \mathrm{CO}_{3}, 300 \mu \mathrm{l}\right)$ was mixed in the reaction mixture and incubated for $30 \mathrm{~min}$ at $40^{\circ} \mathrm{C}$ temperature. The absorbance of the samples was recorded at $765 \mathrm{~nm}$.

Proline concentration was estimated as per the protocol of Bates et al. (1973). Fresh leaves $(0.5 \mathrm{~g})$ were homogenized with $5 \mathrm{ml}$ of $3 \%(w / v)$ sulfosalicylic acid and centrifuged at $20,000 \mathrm{~g}$ for $5 \mathrm{~min}$. The reaction mixture was prepared with $0.5 \mathrm{ml}$ of supernatant, $0.5 \mathrm{ml}$ of glacial acetic acid and $0.5 \mathrm{ml}$ of ninhydrin reagent. This reaction mixture was kept at $100^{\circ} \mathrm{C}$ temperature for $1 \mathrm{~h}$ and reactions were stopped using ice-bath. After cool down the reaction mixture, toluene $(1 \mathrm{ml})$ was supplemented and vigorously mixed for $30 \mathrm{~min}$ until two separate layers were visible. The chromophore contacting toluene (upper layer) was utilized to take the absorbance at $520 \mathrm{~nm}$.

\section{Determination of antioxidative enzymatic assay}

Fresh $0.5 \mathrm{~g}$ leaf tissues were harvested and homogenized in $5 \mathrm{ml}$ of extraction buffer [containing $50 \mathrm{mM}$ phosphate buffer, $2 \mathrm{mM}$ ethylenediaminetetraacetic acid (EDTA), $1 \mathrm{mM}$ phenylmethylsulfoniyl fluoride (PMSF) and $1 \%$ polyvinylpyrrolidone (PVP)] and centrifuged at $12,000 \times g$ at $4{ }^{\circ} \mathrm{C}$ for $15 \mathrm{~min}$. The supernatant was collected and immediately used for the antioxidative enzymatic assay. Superoxide dismutase (SOD) enzyme activity was estimated as per the method of Beauchamp and Fridovich (1971). For SOD estimation reaction mixture containing $50 \mathrm{mM}$ sodium-phosphate buffer $(\mathrm{pH}=7.8)$, $13 \mathrm{mM}$ methionine, $75 \mu \mathrm{M}$ NBT, $100 \mathrm{nM}$ EDTA, $2 \mu \mathrm{M}$ riboflavin and enzyme extract. SOD activity was recorded via measuring the inhibition of photochemical reduction of nitro-blue tetrazolium (NBT) at $560 \mathrm{~nm}$. The catalase 
activity (CAT) was measured as reported by the method of Aebi (1984). For CAT estimation, the reaction mixture contained enzyme extract with $50 \mathrm{mM}$ potassium- phosphate buffer $(\mathrm{pH}=7.0)$ and $24 \mathrm{mM} \mathrm{H}_{2} \mathrm{O}_{2}$. Absorbance was taken at $240 \mathrm{~nm}$ to measure the decomposition of $\mathrm{H}_{2} \mathrm{O}_{2}$. Ascorbate peroxidase (APX) activity was calculated by the method of Chen and Asada (1989). For APX estimation, oxidation of ascorbic acid was started in the reaction mixture by adding $10 \% \mathrm{H}_{2} \mathrm{O}_{2}$. The oxidation rate was recorded by measuring a decrease in absorbance at $290 \mathrm{~nm}$. Glutathione reductase (GR) activity was measured according to the method of Schaedle and Bassham (1977) via measuring the NADPH oxidation at $340 \mathrm{~nm}$ (coefficient of absorbance of $6.2 \mathrm{mM}^{-1} \mathrm{~cm}^{-1}$ ). The reaction mixture for GR activity assessment, contained $50 \mathrm{mM}$ potassium-phosphate buffer ( $\mathrm{pH}=7.8$ ), $2 \mathrm{mM} \mathrm{Na}_{2}$ EDTA, $0.15 \mathrm{mM}$ NADPH (Initiator of reaction), $0.5 \mathrm{mM}$ glutathione oxidized (GSSG) and enzyme extract.

\section{Extraction and estimation of withanolides}

W. coagulans plant leaves were used for withanolides extraction from both control and UV-B exposed plant sets. Extraction of withanolides was completed as stated in the method of Chaurasiya et al. (2008) with some modifications. $2.0 \mathrm{~g}$ fresh leaf tissues were crushed and extracted with $10 \mathrm{ml}$ of methanol: water $(25: 75 \mathrm{v} / \mathrm{v})$ solution at room temperature overnight and filtrate was separated. Repeatedly, the left sample residue was re-extracted with the same volume of methanol [10 ml of methanol: water $(25: 75 v / v)]$ for twice at $4 \mathrm{~h}$ intervals. The filtrate was collected and extracted again with $10 \mathrm{ml} n$-hexane three times. The fraction of methanol was further pooled and extracted three times with $10 \mathrm{ml}$ chloroform. Then, the chloroform fraction was collected and concentrated. Dry concentrated powder $(5 \mathrm{mg})$ of withanolides extract was dissolved in $1.0 \mathrm{ml}$ methanol (HPLC-grade). The HPLC analysis was carried out using the 2707 autosampler 515 HPLC pump with auto injector and 2998 Photodiode array detector. With anolides standard (Natural Remedies Pvt. Ltd.- India) and millipore filtered samples $(30 \mu \mathrm{l})$ were injected to HPLC analysis

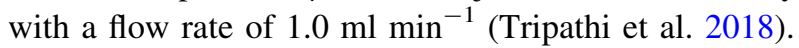

\section{RNA isolation and gene expression pattern}

Healthy leaf tissues $(0.1 \mathrm{~g})$ of UV-B treated and untreated $W$. coagulans plants were harvested and ground in liquid nitrogen for the extraction of RNA using TRIZOL reagent (GIBCO-BRL). After centrifugation at $12,000 \times \mathrm{g}$ for 15 min at $4{ }^{\circ} \mathrm{C}$, the upper aqueous layer containing RNA was carefully removed. Per $1 \mathrm{~mL}$ of TRIZOL, $0.5 \mathrm{ml}$ isopropyl alcohol was mixed and incubated for $10 \mathrm{~min}$ to precipitate RNA. Again, RNA containing suspension was centrifuged for $10 \mathrm{~min}$ at $12,000 \times \mathrm{g}$ and the RNA pellet was washed with $75 \%$ cold ethanol. The isolated RNA pellet was re-suspended in $50 \mu \mathrm{l}$ DEPC treated water and quantified with the use of Nano Drop spectrophotometer (Thermo scientific). Primer 3 software was utilized for the withanolides biosynthesis genes expression related primers designing, which are listed in Table S1. Semi-quantitative RT-PCR was performed to analyse transcript level using thermo cycler (Bio-Rad). RT-PCR produced amplified bands intensity were measured on $2 \%$ agarose gel with the help of Gel-DOC EZ imager (Bio-Rad) using Quantity One software (Bio-Rad). To confirm the equal concentration of RNA in different samples, ACTIN was used as a control.

\section{Statistical analysis}

Minimum three biological replicates per treatment were used for performing all the experiments and measurements were repeated three times. Acquired data were presented as mean value $\pm \mathrm{S}$. E. All the statistical analysis was accomplished with SPSS (Version 16.0), through one-way ANOVA statistical significance was assessed by Tukey's post-hoc mean separation test $(P<0.05)$. The graphical presentations were constructed with Sigma Plot (version 11.0). Pictorial correlation analysis was performed through Past3 software. Further, a heat-map was prepared with Bioconductor-R (http://www.bioconductor.org).

\section{Results}

\section{Effect of UV-B on photosynthetic pigments}

The photosynthetic pigments concentration of $W$. coagulans was estimated under UV-B exposure (Fig. 1). UV-B treatment significantly decreased total chlorophyll content in $W$. coagulans in a time dependent manner. In the plants, with $5 \mathrm{~h}$ UV-B exposure $\operatorname{chl} a, \operatorname{chl} b$ and total chlorophyll content were maximum reduced by $40.7 \%, 65.4 \%$ and $48.3 \%$ respectively. However, carotenoid content was significantly improved with UV-B exposure with a maximum 1.36-fold increase under $5 \mathrm{~h}$ treatment (Table 1).

\section{Impact of UV-B exposure on anthocyanin, chlorophyll fluorescence and gas exchange parameters}

Our observations showed that UV-B exposed plant sets produced significantly higher concentrations of anthocyanin as compared to the control plants. Maximum concentration of anthocyanin $\left(0.59 \pm 0.08 \mathrm{~g} \mathrm{FW}^{-1}\right)$ was measured with $5 \mathrm{~h}$ treatment of UV-B exposure (Table 1). The impact of UV-B exposure was also estimated on 


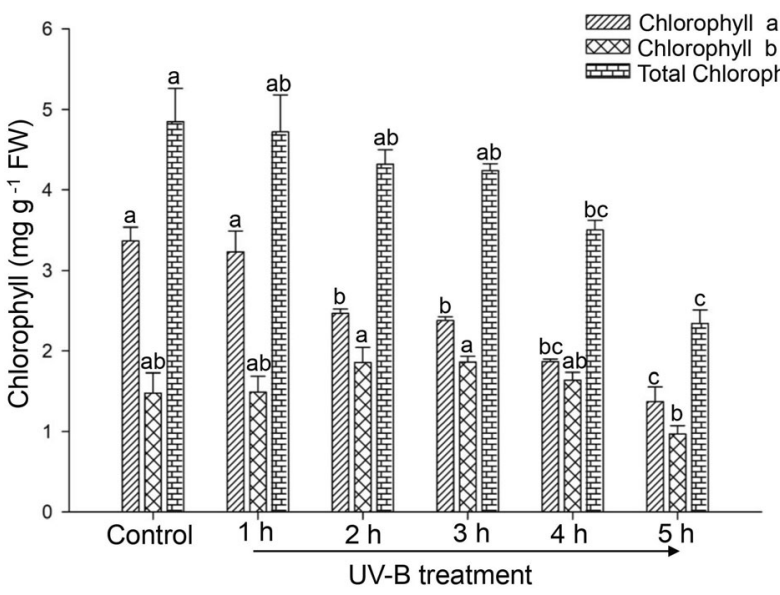

Fig. 1 Effect of UV-B on photosynthetic pigment chlorophyll a, chlorophyll $\mathrm{b}$ and total chlorophyll of Withania coagulans (L.) Dunal. Bars represented mean value $\pm \mathrm{SE}(\mathrm{n}=3)$. Different letters represent significant difference $P<0.05$; by implementing Tukey's multiple comparison tests chlorophyll fluorescence parameters for analysing the information with respect to plant photosynthesis. UV-B exposure showed no significant effect on $\mathrm{Fv} / \mathrm{Fm}$ ratio up to $3 \mathrm{~h}$ treatment, both control and short-term UV-B treated plants exhibited almost identical Fv/Fm (0.79-0.84) ratio (Table 1). Evaluation of gas exchange parameters showed that UV-B exposure time leading to gradual decrease in $W$. coagulans photosynthetic rate $(P n)$, stomatal conductance $(g s)$, transpiration rate $(T r)$ and internal $\mathrm{CO}_{2}(C i)$ level (Table 1). The photosynthetic rate was observed significantly decrease after $1 \mathrm{~h}$ treatment of UV-B whereas the lowest value was found at $5 \mathrm{~h}$ treatment with 7.6-fold lesser than the control plant. The impact of UV-B on $g s$ was found significantly decreased respect with the control plant. The minimum significant value of $g s$ was recorded at $5 \mathrm{~h}$ UV-B exposure $\left(0.015 \pm 0.002 \mathrm{mmol} \cdot \mathrm{m}^{-2} \cdot \mathrm{s}^{-1}\right)$. The W. coagulans leaves supplemented with short-term UV-B exposure exhibited significant minimum $\operatorname{Tr}$ compared with

Table 1 Effect of UV-B on physio-biochemical behavior of Withania coagulans (L.) Dunal

\begin{tabular}{|c|c|c|c|c|c|c|}
\hline \multirow[b]{2}{*}{ Parameters } & \multicolumn{6}{|l|}{ UV-B Treatment } \\
\hline & Control & $1 \mathrm{~h}$ & $2 \mathrm{~h}$ & $3 \mathrm{~h}$ & $4 \mathrm{~h}$ & $5 \mathrm{~h}$ \\
\hline $\begin{array}{l}\text { Carotenoid (mg g } \\
-1 \mathrm{FW})\end{array}$ & $1.55 \pm 0.10^{\mathrm{b}}$ & $1.71 \pm 0.12^{\mathrm{ab}}$ & $1.72 \pm 0.06^{\mathrm{ab}}$ & $1.77 \pm 0.12^{\mathrm{ab}}$ & $1.95 \pm 0.08^{\mathrm{ab}}$ & $2.13 \pm 0.05^{\mathrm{a}}$ \\
\hline $\begin{array}{l}\text { Anthocyanin (per } \\
\mathrm{g}^{-1} \mathrm{FW} \text { ) }\end{array}$ & $0.28 \pm 0.03^{\mathrm{b}}$ & $0.39 \pm 0.01^{\mathrm{ab}}$ & $0.50 \pm 0.04^{\mathrm{ab}}$ & $0.56 \pm 0.07^{\mathrm{ab}}$ & $0.57 \pm 0.04^{\mathrm{ab}}$ & $0.59 \pm 0.08^{\mathrm{a}}$ \\
\hline $\mathrm{Fv} / \mathrm{Fm}$ & $0.81 \pm 0.007^{\mathrm{a}}$ & $0.80 \pm 0.011^{\mathrm{a}}$ & $0.80 \pm 0.018^{\mathrm{a}}$ & $0.80 \pm 0.012^{\mathrm{a}}$ & $0.79 \pm 0.008^{\mathrm{ab}}$ & $0.73 \pm 0.007^{\mathrm{b}}$ \\
\hline $\begin{array}{l}\text { Photosynthetic } \\
\text { rate }\left(\mu \mathrm{mol} \cdot \mathrm{m}^{-2}\right. \\
\left.\mathrm{s}^{-1}\right)\end{array}$ & $2.98 \pm 0.19^{\mathrm{a}}$ & $2.93 \pm 0.17^{\mathrm{a}}$ & $1.68 \pm 0.33^{\mathrm{b}}$ & $1.42 \pm 0.18^{\mathrm{b}}$ & $1.36 \pm 0.19^{\mathrm{b}}$ & $0.39 \pm 0.05^{\mathrm{c}}$ \\
\hline $\begin{array}{l}\text { Stomatal } \\
\text { conductance } \\
\left(\mathrm{mmol} \cdot \mathrm{m}^{-2} \cdot \mathrm{s}\right. \\
\left.{ }_{-1}\right)\end{array}$ & $0.037 \pm 0.003^{\mathrm{a}}$ & $0.032 \pm 0.003^{\mathrm{a}}$ & $0.026 \pm 0.007^{\mathrm{ab}}$ & $0.028 \pm 0.005^{\mathrm{ab}}$ & $0.025 \pm 0.003^{\mathrm{ab}}$ & $0.015 \pm 0.002^{\mathrm{b}}$ \\
\hline $\begin{array}{l}\text { Transpiration rate } \\
\left(\mathrm{mmol} \cdot \mathrm{m}^{-2} \cdot \mathrm{s}\right. \\
\quad-1)\end{array}$ & $2.03 \pm 0.17^{\mathrm{a}}$ & $1.84 \pm 0.16^{\mathrm{ab}}$ & $1.50 \pm 0.40^{\mathrm{b}}$ & $1.48 \pm 0.23^{\mathrm{b}}$ & $1.15 \pm 0.14^{\mathrm{bc}}$ & $0.56 \pm 0.07^{\mathrm{c}}$ \\
\hline $\begin{array}{l}\text { Internal } \mathrm{CO}_{2} \\
\quad\left(\mathrm{mmol} \cdot \mathrm{mol}^{-1}\right)\end{array}$ & $347.9 \pm 5.9^{\mathrm{a}}$ & $345.7 \pm 5.9^{\mathrm{a}}$ & $344.3 \pm 12.4^{\mathrm{a}}$ & $280.6 \pm 14.5^{\mathrm{ab}}$ & $293.2 \pm 4.3^{\mathrm{ab}}$ & $229.2 \pm 11.2^{\mathrm{b}}$ \\
\hline $\begin{array}{l}\text { Free radical } \\
\text { scavenging } \\
\text { activity (DPPH } \\
\% \text { inhibition) }\end{array}$ & $69.62 \pm 1.54^{b}$ & $71.40 \pm 2.59^{\mathrm{b}}$ & $78.10 \pm 2.01^{\mathrm{ab}}$ & $87.96 \pm 2.24^{\mathrm{a}}$ & $70.41 \pm 1.28^{\mathrm{b}}$ & $46.15 \pm 0.74^{\mathrm{c}}$ \\
\hline $\begin{array}{l}\text { Lipid } \\
\text { peroxidation } \\
\text { (MDA mm g } \\
\text { FW) }\end{array}$ & $1.59 \pm 0.05^{\mathrm{c}}$ & $1.66 \pm 0.09^{c}$ & $1.70 \pm 0.05^{\mathrm{c}}$ & $2.39 \pm 0.05^{\mathrm{b}}$ & $2.83 \pm 0.03^{\mathrm{a}}$ & $2.99 \pm 0.06^{\mathrm{a}}$ \\
\hline $\begin{array}{l}\text { Phenol (mg g } \\
\text { FW) }\end{array}$ & $396.2 \pm 17.17^{\mathrm{c}}$ & $483.3 \pm 27.77^{\mathrm{bc}}$ & $541.9 \pm 21.32^{\mathrm{b}}$ & $552.8 \pm 12.20^{\mathrm{b}}$ & $680.9 \pm 18.93^{\mathrm{a}}$ & $699.2 \pm 18.10^{\mathrm{a}}$ \\
\hline $\begin{array}{l}\text { Proline }(\mu \text { mole } g \\
\left.{ }_{-1} \mathrm{FW}\right)\end{array}$ & $5.01 \pm 0.41^{\mathrm{b}}$ & $6.42 \pm 0.29^{\mathrm{ab}}$ & $6.21 \pm 0.22^{\mathrm{ab}}$ & $6.51 \pm 0.16^{\mathrm{ab}}$ & $6.99 \pm 0.37^{\mathrm{ab}}$ & $7.08 \pm 0.50^{\mathrm{a}}$ \\
\hline
\end{tabular}

Each value represents the mean value \pm SE. Mean followed by the same letters in each column are not significantly different at $P<0.05$ according to Tukey's multiple range tests 
the control plants. Similarly, $C i$ was also found decreased with UV-B treatment in comparison to control plants but non-significant difference was evaluated in $\mathrm{Ci}$ concentration up to $2 \mathrm{~h}$ UV-B exposure.

\section{Impact on lipid peroxidation and free radical scavenging activity}

Lipid peroxidation level (with reference to MDA concentration) was found consequently elevated in a time dependent manner of UV-B exposure. As compared to control plants, up to $2 \mathrm{~h}$ UV-B treatment non-significant alteration was recorded in MDA concentration. However, maximum significant enhancement in MDA concentration was estimated in 4 and $5 \mathrm{~h} \mathrm{UV-B}$ treated plants up to 41.5 and $46.8 \%$, respectively, in contrast to the control plant sets (Table 1). Percent (\%) inhibition of DPPH was significantly increased in $W$. coagulans leaves with gradual increase in UV-B exposure time up to $3 \mathrm{~h}$. In response to UV-B exposure, free radical scavenging activity was found to be maximum $(87.96 \pm 2.24 \%)$ in plants treated under 3 h UV-B light, which was $\sim 18 \%$ higher than the control (Table 1).

\section{Impact of UV-B on total phenol and proline content}

Total phenol and proline contents both were elevated in $W$. coagulans under UV-B exposure as a part of defense strategy. Phenol content was found significantly high with $4 \mathrm{~h}$ and $5 \mathrm{~h}$ UV-B treatment as 1.72 and 1.76-fold enhancement, respectively than the control plants (Table 1). Similarly, proline concentration was also found significantly increased with UV-B exposure, where maximum proline content was recorded for $5 \mathrm{~h}$ UV-B treated plants set $\left(7.08 \pm 0.50 \mu\right.$ mole $\left.\mathrm{g}^{-1} \mathrm{FW}\right)$ (Table 1).

\section{Correlation analysis}

The physiological and biochemical parameters of UV-B treated and untreated plants were subjected to correlation analysis. Figure 2 clearly depicting a symbolic and significant correlation between treated and nontreated plant's physiology and biochemical parameters. A significant positive correlation was found among total chlorophyll content, $\mathrm{Fv} / \mathrm{Fm}$ ratio and free radical scavenging activity of plant. Anthocyanin and carotenoids were also found positively correlated with phenol and proline contents. Significant negative correlation was also found between chlorophyll and lipid peroxidation.
Impact of UV-B radiation on antioxidative enzymes activity

The data shown in Fig. 3 illustrate that the activities of antioxidative defense enzymes were significantly modified in $W$. coagulans under UV-B exposure. SOD enzyme activity was significantly enhanced with the initial short period (up to $2 \mathrm{~h}$ ) UV-B exposure. After $3 \mathrm{~h} \mathrm{UV-B}$ treatment, non-significant difference was observed in SOD activity compared with the control plants. Similarly, significant activity increase was observed for the APX and CAT activity with the UV-B exposure. Maximum activities of APX and CAT were recorded under $3 \mathrm{~h} \mathrm{UV-B} \mathrm{exposure,}$ which were $\sim 1.87$ and 2.36-fold, respectively higher than the control plants. A significant variation was acquired between UV-B treated and untreated plant sets in response to GR enzyme activity. The significant maximum GR activity was recorded against short-term UV-B exposure in W. coagulans. In contrast to control plant, 2, 3 and $4 \mathrm{~h} \mathrm{UV-}$ $\mathrm{B}$ exposed plants, GR activity was found to be maximum 5.66, 6.02 and 5.08-fold, respectively.

\section{Withanolides quantification and expression analysis of their biosynthesis related genes under UV-B exposure}

Figure 4 depicting a significant increase was found in withanolide A and withaferin A content in UV-B treated $W$. coagulans plants. After that $1 \mathrm{~h}$ UV-B exposure, the maximum withanolide A concentrations were measured in 3 and $4 \mathrm{~h}$ treated plants which were approximately 3.42fold higher than the control plants. Withaferin A content was also found elicited with UV-B exposure and the highest concentration was recorded with $3 \mathrm{~h}$ treatment that was 1.38 -fold maximum as compared to untreated plants.

The transcription pattern of six key withanolides biosynthetic pathway genes such as HMG-CoA reductase $(H M G R)$, Farnesyl pyrophosphate synthase (FPPS), Squalene synthase $(S Q S)$, 1-deoxy-D-xylulose-5-phosphate reductoisomerase $(D X R), 1$-deoxy-D-xylulose-5-phosphate synthase (DXS) and Cytochrome P450 51G1 (CYP51G1) were analysed via semi-quantitative RT-PCR in the UV-B treated and non-treated plants (Fig. 5a). It was observed that $H M G R$ gene transcripts level was up-regulated with the treatment of in-vitro UV-B. The significant maximum over-expression of $H M G R$ was found in $3 \mathrm{~h} \mathrm{UV-B}$ treated plants which was 1.78 -fold higher than the control plants. In the MEP pathway, $D X R$ and $D X S$ genes exhibited overexpression in the plants after $2 \mathrm{~h} \mathrm{UV-B}$ exposure. $D X R$ was upregulated 1.37, 1.21 and 1.27-folds with the treatments 3, 4 and $5 \mathrm{~h}$ UV-B respectively. Similarly, DXS was also analysed significantly over express (2.0 and 2.17-folds higher than the control) in 3 and $4 \mathrm{~h}$ UV-B treated plants. 


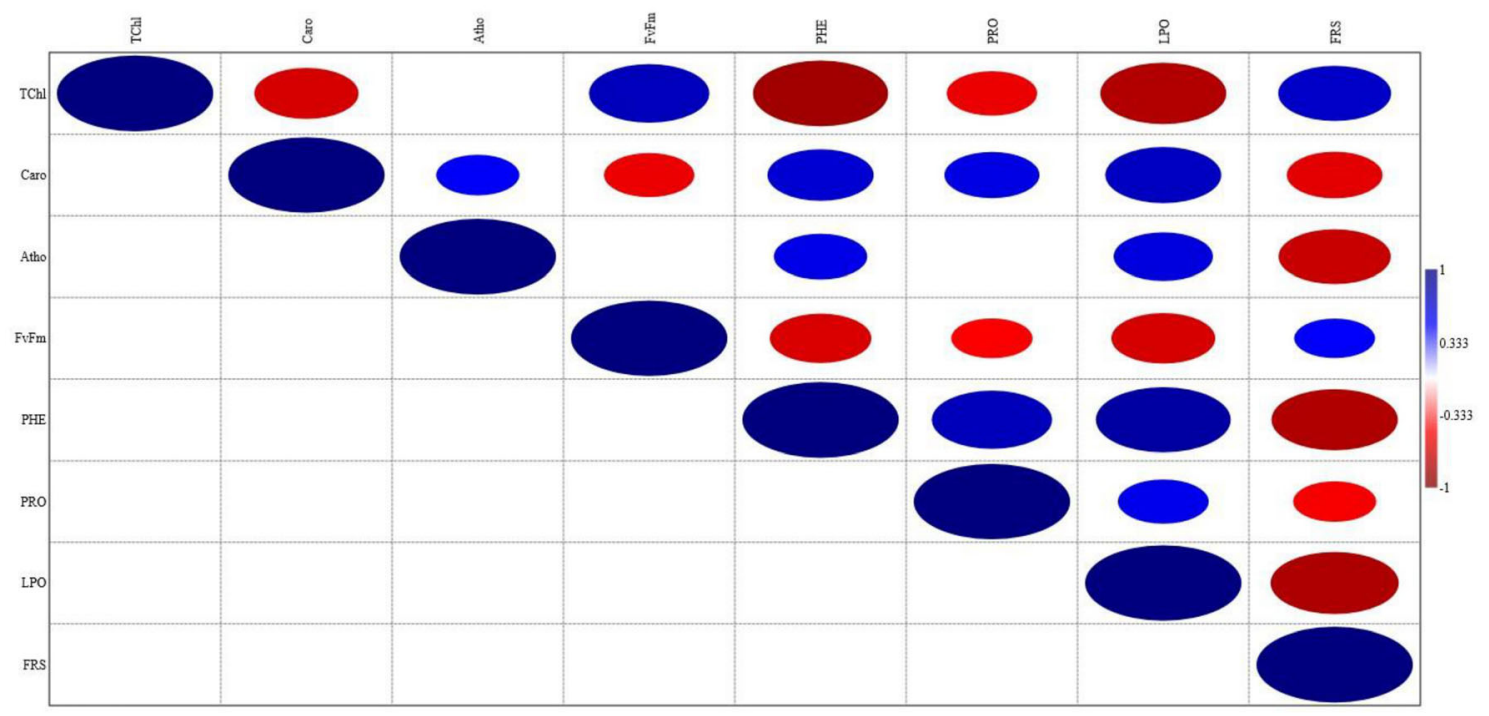

Fig. 2 Pictorial presentation of correlation analysis between the different physiological and biochemical parameters of control and UV-B treated Withania coagulans (L.) Dunal. (Tchl: Total

After isoprenogenesis, steroids biosynthesis related genes such as FPPS, SQS and CYP51G1 were also found upregulated with the treatment of UV-B. The FPPS gene transcript was highly expressed (1.95-fold) when UV-B irradiation given for $3 \mathrm{~h}$. The obtained results clearly showed that the relative expression of $S Q S$ was increased by 1.16 and 1.20 -folds with 3 and $4 \mathrm{~h}$ treatments, respectively. Among, all the tested genes only CYP51G was maximum up-regulated with $1 \mathrm{~h}$ UV-B exposure, whereas rest of genes transcript levels were found maximum with 3 and $4 \mathrm{~h}$ UV-B. The pattern of withanolides biosynthetic pathway genes expression in different UV-B treated plant sets has also been by heat-map analysis using complete linkage and euclidean distance matrix (Fig. 5b). Heat-map shows two major clusters of UV-B treated plants, in which one major cluster having 3, 4 and $5 \mathrm{~h}$ UV-B treated plant sets, while another cluster having control, 1 and $2 \mathrm{~h}$ UV-B treated plant sets. Heat-map also depicting that 3 and $4 \mathrm{~h}$ UV-B radiation exposed plant sets forms a separate cluster from all other UV-B treated and untreated plant groups with regard to high transcript level of withanolides biosynthesis related genes.

\section{Discussion}

The present work has shown that UV-B exposure given for a short time period might be used to modulate physiological and biochemical parameters of pharmacologically important endangered plant $W$. coagulans with the enhancement of bioactive compounds. We strengthen the concept of elicitation of secondary metabolites production chlorophyll, Caro: carotenoids; Atho: Anthocyanin; FvFm: Fv/Fm; PHE: Phenol; PRO: Proline; LPO: Lipid peroxidation; FRS: Free radical scavenging activity)

with the perception of UV-B, which had been previously reported in other medicinally important plants (Takshak and Agrawal 2019; Zhang et al. 2018; Ghasemi et al. 2019). To the best of our observation, this is the first information that deciphering the physio-biochemical changes in W. coagulans to counteract and recover UV-B exposure given under in-vitro conditions. A number of investigations have pointed out that the effects of UV-B radiation are species specific and depend on interaction with other environmental factors (Zlatev et al. 2012). Hence, to understand the particular consequences of UV-B radiation on plants, experiments were performed under invitro conditions.

In our study, total chlorophyll concentration was significantly decreased with in-vitro UV-B supplementation. A lower level of chlorophyll was might be observed because of the suppression of chlorophyll biosynthesis or chlorophyll degradation under UV-B irradiation (Choi and Roh 2003; Zvezdanović et al. 2009). Our results indicated that UV-B exposure severely damages the biosynthesis of chl $a$ as compared to $c h l b$. Whereas, $c h l b$ was found slightly enhanced with 2 and 3 h UV-B treatment. Similarly, Salama et al. (2011) have been reported that UV-B supplementation enhanced the $c h l b$ content in Rumex vesicarius $\mathrm{L}$. Carotenoids is a light harvesting complex that protect chlorophyll molecules from photo-oxidative damage under excessive excitation energy state created by UVB exposure (Gill and Tuteja 2010; Rai et al. 2011). The energy channelizing ability of carotenoids is due to the isoprenic chain residues, which provide simple energy recovery from the excited molecules and excess energy dissipation as heat (Ghasemi et al. 2019). The biosynthesis 

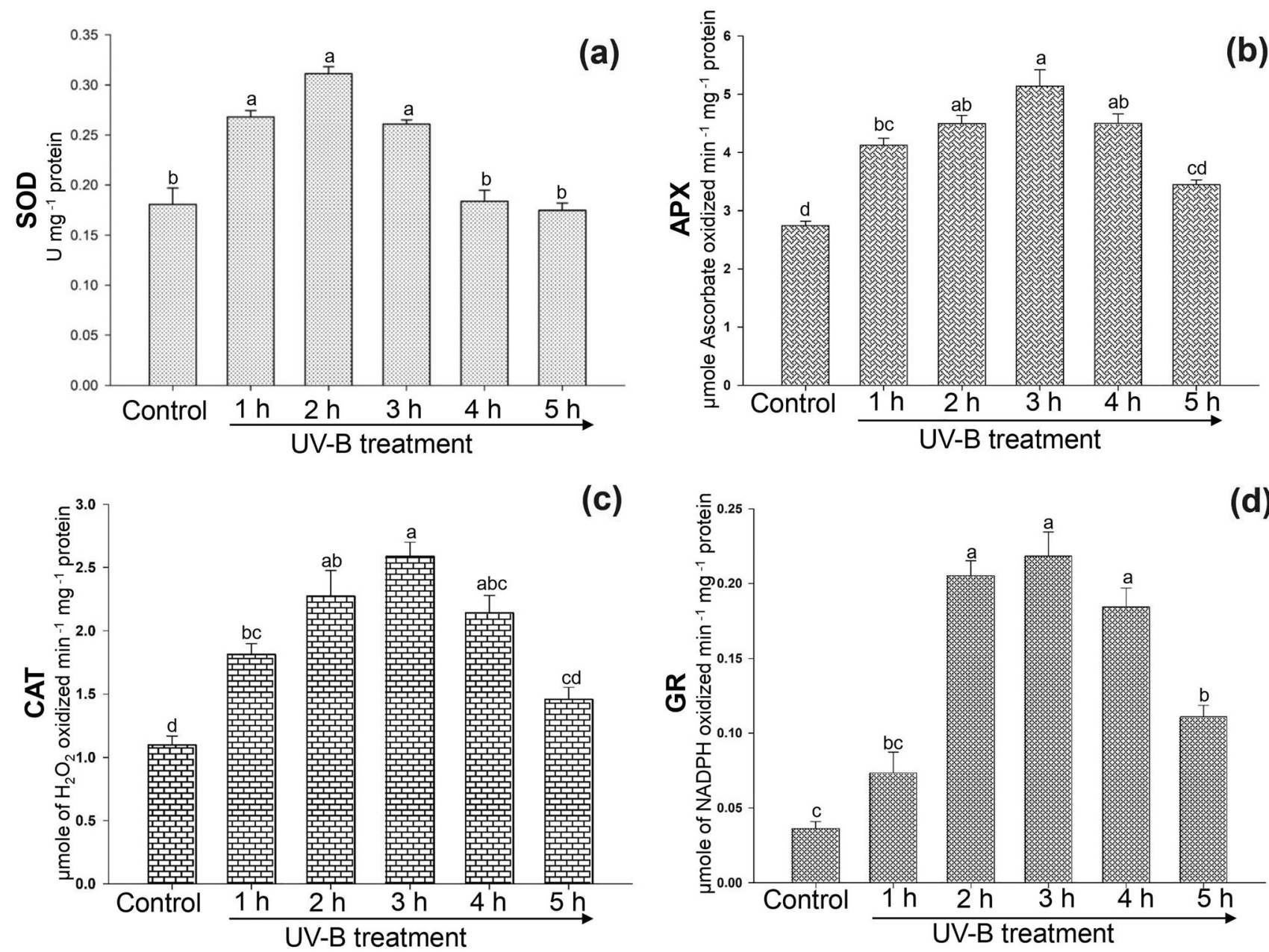

Fig. 3 Effect of UV-B on antioxidative enzymes activity of Withania coagulans (L.) Dunal. a Superoxide dismutase (SOD); b Ascorbate peroxidase (APX); c Catalase (CAT); and $\mathbf{d}$ Glutathione reductase

(GR). Bars represented mean value $\pm \mathrm{SE}(\mathrm{n}=3)$. Different letters represent significant difference $P<0.05$; by implementing the Tukey's multiple comparison test

(a)
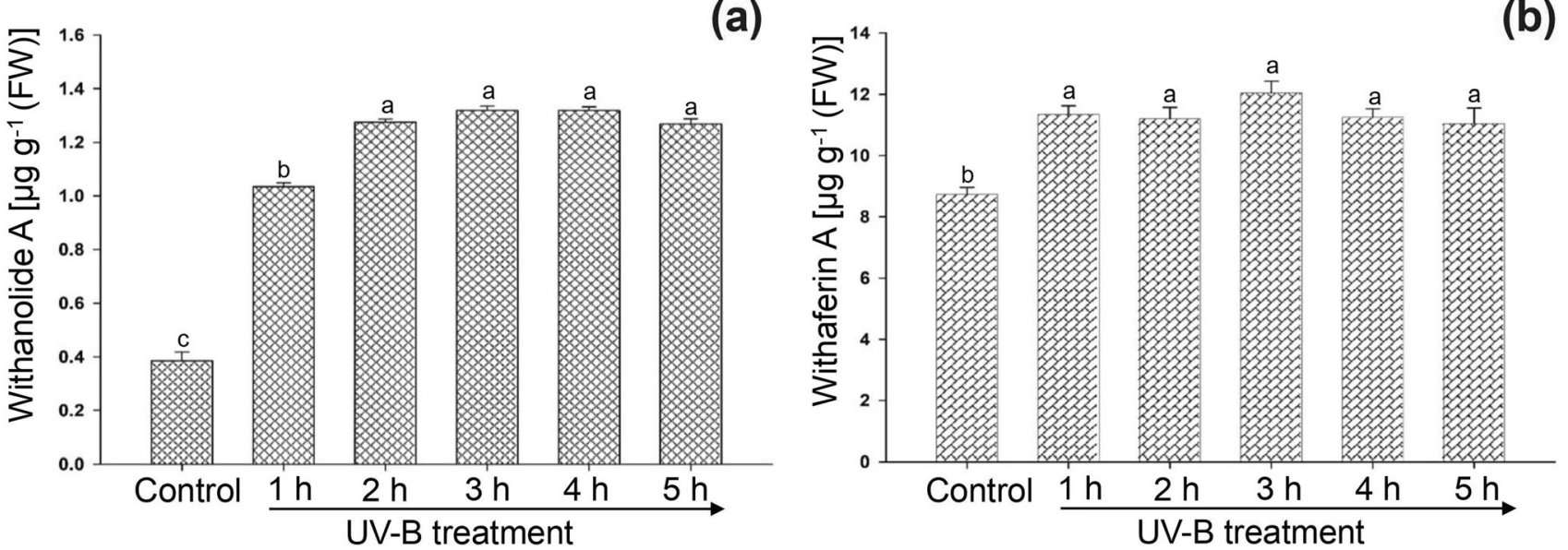

Fig. 4 Effect of UV-B on withanolides production in Withania coagulans (L.) Dunal (a) Withanolide A; and (b) Withaferin A. Bars represented mean value $\pm \mathrm{SE}(\mathrm{n}=3)$. Different letters represent significant difference $P<0.05$; by implementing the Tukey's multiple comparison test 


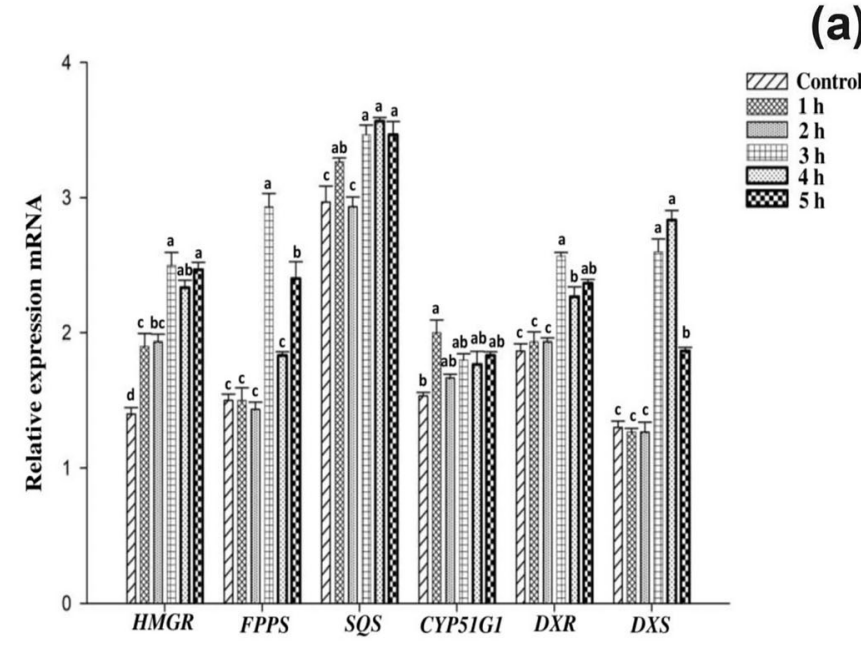

Fig. 5 Semi quantitative RT-PCR gene expression analysis for withanolides biosynthesis pathway related genes. a Histogram illustrating relative transcript level of genes as determined by the RT-PCR analysis; and b Heatmap depicting relative transcript level of genes (as fold change) as determined by the RT-PCR analysis. Bars represented mean value $\pm \operatorname{SE}(n=3)$. Different letters represent

of carotenoid is regulated by light quality and UV-B receptors. In 2017, Shen et al. analyzed the over-expression of phytoene synthase gene that accelerates the process of carotenogenesis under UV-B supplementation. In our system, carotenoid was gradually increased with UV-B time exposure. Therefore, we can state that enhanced content of carotenoids might have offered protection against supplemented UV-B in W. coagulans. Similar information has been also reported for other medicinally and economically considerable plants like W. somnifera (Takshak and Agrawal 2014a), Artemisia annua (Pandey and Pandey-Rai 2014a), Capsicum annuum (León-Chan et al. 2017).

Our results indicated that under enhanced UV-B exposure anthocyanin content was significantly increased, suggesting UV-B light has the potential to up regulate anthocyanin production (Sztatelman et al. 2015). Whereas anthocyanin has ability to work as photo-protective agent that can alleviate the damage produced by UV-B light exposure (Steyn et al. 2002). The increase in anthocyanin content under UV-B exposure was in accordance with the previous studies of Ravindran et al. (2010), Pandey and Pandey-Rai (2014b), Takshak and Agrawal, (2018) etc. This increase in anthocyanin level is may be due to upregulation of the anthocyanin producing genes under UVB supplementation (Ban et al. 2007; Guo et al. 2008). Similarly, Wu et al. (2016) explained the role of UV RESISTANCE LOCUS8 (UVR8) as UV-B photoreceptor in radish (sprouts) and they observed that the transcript level of UVR8 was increased in a similar trend of anthocyanin accumulation.

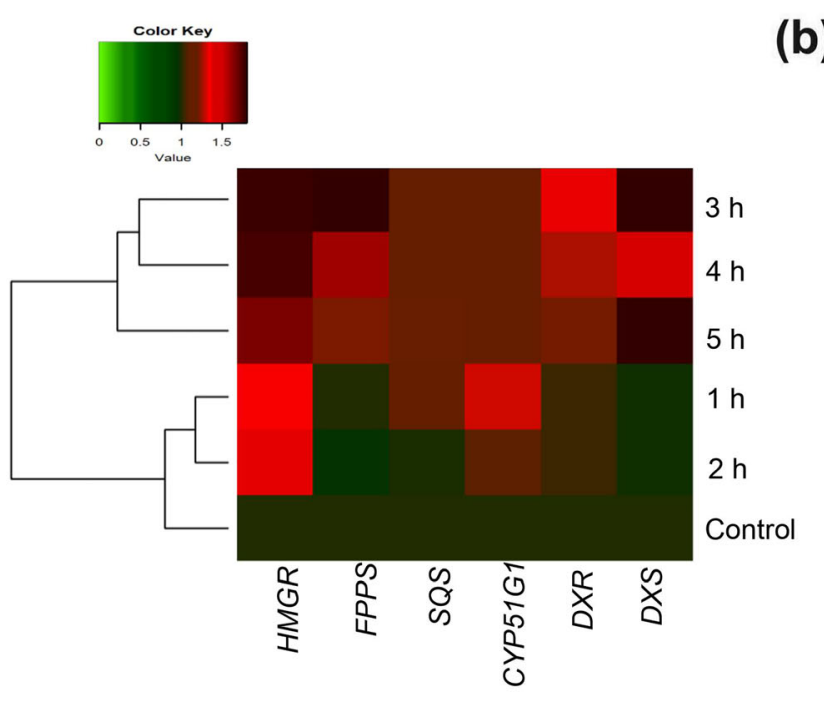

(b)

significant difference $P<0.05$; by implementing the Tukey's multiple comparison test. [HMG-CoA reductase (HMGR), Farnesyl pyrophosphate synthase (FPPS), Squalene synthase (SQS), 1-deoxyD-xylulose-5-phosphate reductoisomerase $(D X R)$, 1-deoxy-D-xylulose-5-phosphate synthase (DXS) and Cytochrome P450 51G1 (CYP51G1)]

Chlorophyll fluorescence is an effective physiological indicator of plant health under the exposure of environmental constraints (Alyemeni et al. 2018; Akhter et al. 2021). Assessment of chlorophyll fluorescence parameters clearly demonstrated that short-term UV-B exposure (up to $3 \mathrm{~h})$ non-significantly altered $\mathrm{Fv} / \mathrm{Fm}$ in $W$. coagulans, while long time UV-B treatment exerted negative effect on Fv/Fm. This observation revealed that short-term UV-B treatment not effected the primary photochemical efficiency of photosystem-II (PS-II). However, the reduction in Fv/Fm with long time UV-B exposure indicated the destruction of antenna pigments and inhibition of PS-II. According to Szilárd et al. (2007) UV-B long time precipitation hampers the function of water-oxidizing complex of PS-II in plants. Moreover, a significant reduction in photosynthetic rate, stomatal conductance, transpiration rate and internal $\mathrm{CO}_{2}$ concentrations were observed with UV-B exposure. A meta-analysis has suggested that net photosynthetic rate negatively affected in herbaceous plants under UV-B exposure ( $\mathrm{Li}$ et al. 2010), whereas previously it has also been reported that it might be correlated with the inhibitory activity of rubisco (Yu et al. 2013). Cechin et al. (2008) noted that in Helianthus annuиs L. reduced photosynthetic rate was indirectly associated with stomatal conductance that is a most variable factor which alters the effect of UV-B on plants. Similar to our result, UV-B exposure has been shown to decrease gas exchange parameters in many other plants like Glycine max L. (Choudhary and Agrawal 2015), Triticum polonicum L. (Yan et al. 2016), Chenopodium quinoa (Huarancca Reyes 
et al. 2018), Populus alba and P. russkii (Ma et al. 2016). In the present study, we also demonstrated the lipid peroxidation level under UV-B exposure to analyse the oxidative damage within the cellular membrane. In $W$. coagulans, UV-B supplementation increased MDA content gradually with UV-B exposure, which is a well-known indicator of membrane damage in plant cells (Khator et al. 2020). Significant increase in MDA content after 3 h UV-B exposure suggested that UV-B radiation created oxidative damage cannot be counteracted by an antioxidative defense mechanism. Increase in lipid peroxidation under UV-B radiation was also earlier recorded by Rai et al. (2011) and Prasad et al. (2005) etc.

As the protective strategy, free radicals scavenging activity of plants is induced under UV-B supplementation that suppresses oxidative stress (Inostroza-Blancheteau et al. 2016; Takshak and Agrawal 2015). The present results showed the increased percent inhibition of DPPH with short-term UV-B exposure in W. coagulans, which reflected the potential to modulate their physiological processes to combat the oxidative stress up to $3 \mathrm{~h} \mathrm{UV-B}$ exposure. Studies reported that phenols are key regulators under abiotic stress conditions in plants with playing a crucial role in the regulation of photosynthesis, minerals uptake, hormonal regulation, cell division, signal transduction and reproduction (Sharma et al. 2019; Bali et al. 2019; Ahanger et al. 2019; Jabeen et al. 2020). Phenols also participate in the enhanced tolerance to oxidative damage under elevated UV-B supplementation (Kondo and Kawashima 2000). In our study, significant enhancement in phenol concentration was presented under short-term UVB exposure supported with many previous studies (Mosadegh et al. 2018; Pandey and Pandey-Rai 2014b; Kondo and Kawashima 2000). Enhanced synthesis of phenolic compounds under UV-B supplementation shows better adaptability to adverse effects in plants and probably it is induced with the upregulation of phenylalanine lyase (PAL) (Cantarello et al. 2005). Proline not only performs as a free radical scavenger to neutralize ROS but also act as a stabilizer of plant cell membrane under stress condition (Dhir et al. 2014; Khator and Shekhawat 2019). According to Salama et al. (2011) proline is working as a protective agent against increased peroxidation levels caused by UV$\mathrm{B}$ radiation. The outcome of this study indicated that the proline concentration was significantly increased with UV$\mathrm{B}$ treatment that also indicated the presence of tolerance to short-term UV-B exposure in W. coagulans.

We also observed differential behaviour in antioxidative enzymes activities in W. coagulans under UV-B exposure. Maximum significant enhancement in SOD, CAT, APX and GR activities were recorded up to $3 \mathrm{~h}$ UV-B supplementation. The results of this study are in accordance with the previous studies that described the progression of the antioxidative defense systems with short-term UV-B exposure in the plants (Inostroza-Blancheteau et al. 2016; Takshak and Agrawal 2014a; Pandey and Pandey-Rai 2014b).

Terpenoids quantification in various medicinal plants using HPLC analysis has been previously reported (Mathur and Shekhawat 2013). Since, the UV-B radiation affects the secondary metabolism, we also analysed here whether the UV-B can regulate therapeutically require secondary metabolites of $W$. coagulans i.e., triterpenoid withanolides. We quantify the withanolide A and withaferin A content in $W$. coagulans under the supplementation of low dose $\left(2.8 \mathrm{~W} \mathrm{~m}^{-2}\right)$ short-term UV-B through HPLC along with analyse the transcription level of mevalonate and MEP pathway intermediate genes. Among all the UV-B treatments, $3 \mathrm{~h}$ supplementation maximum enhanced the contents of both withanolide A and withaferin A with 3.42 and 1.38 -folds, respectively. Earlier many studies also indicated a close relationship between various biotic/abiotic elicitors and withanolides biosynthesis in solanaceous plants like W. somnifera and Physalis species (Takshak and Agrawal 2014b; Singh et al. 2015; Ahlawat et al. 2017; Şahin 2019). However, as far as we know there are no previous studies explaining the impacts of abiotic stresses on withanolides biosynthesis in W. coagulans.In 2014b, Takshak and Agrawal stated that withaferin A content was increased under the supplementation of UV-B in W. somnifera. However, they have also reported adverse effects of UV-B on withanolide A content. In W. somnifera similar trend of enhancement for withanolides concentration with UV-B supplementation was found under other abiotic stresses like drought (Singh et al. 2015). Thus, our study found more advantageous due to enhancement of both withaferin $\mathrm{A}$ and withanolide $\mathrm{A}$ in $W$. coagulans under UV-B supplementation. Increase in withanolides content under UV-B exposure might be due to the up-regulation of their biosynthetic genes. Therefore, for the validation of withanolides quantitative measurements, we analyse the transcript level of the corresponding biosynthesis related genes under UV-B exposure. Our results showed significant over-expression of HMGR, DXR and DXS genes with short-term UV-B treatment. Terpene biosynthesis related genes such as FPPS, SQS and CYP51G1 were also found up-regulated with the $3 \mathrm{~h}$ treatment of UV-B. According to the earlier reports this study explained the over expression of terpenes biosynthesis related genes under UV-B exposure (Li et al. 2011; Rai et al. 2011; Ghasemi et al. 2019). In such a way, this study encourages us to elicitate triterpenoid withanolides production in $W$. coagulans with the help of UV-B short-term exposure. 


\section{Conclusion}

The outcome of this study provides evidence that the impact of short-term (up to $3 \mathrm{~h}$ ) UV-B radiation causes significant alterations in physiological and defense responses of $W$. coagulans. Up to $3 \mathrm{~h}$ exposure, UV-B radiation creates mild stress and negatively affects photosynthetic machinery which was rectified with the acceleration of antioxidative defense mechanism and accumulation of UV-B absorbing protective compounds (such as carotenoids, anthocyanin, phenol, proline etc.). Simultaneously, short-term UV-B supplementation improves the medicinal efficiency of $W$. coagulans with the enhanced in-planta withanolides concentration. The increased withanolide content after UV-B exposure correlated well with up- regulation of key withanolides biosynthetic genes. Overall, this study suggests the potential role of short-term UV-B exposure in modulation of the plant physiological behavior with the enhanced production of bioactive secondary metabolites (like withanolides) thereby improving the medicinal virtue of $W$. coagulans for the benefit of mankind.

Supplementary InformationThe online version contains supplementary material available at https://doi.org/10.1007/s12298021-01046-7.

Acknowledgements We are thankful to CAS- Botany (BHU), DSTPURSE and DST-FIST programmes for providing funds to Department of Botany, Institute of Science, Banaras Hindu University. Authors are acknowledged Dr. Krishna Kumar Rai and Ms. Renu Rawal for providing assistance during heat-map preparation and pictorial correlation analysis. Deepika Tripathi is thankful to CSIR/ UGC- New Delhi, India for providing financial support during experiments and Department of Biotechnology for financial assistance (as awarding DBT-RA fellowship) during manuscript preparation.

Author's contribution DT and SPR designed the experimental work. All experiments were performed by DT. DT wrote the manuscript, RPM helped during editing and SPR approved the final manuscript after editorial help.

\section{Declarations}

Conflict of interest There are no conflicts of interest between authors.

\section{References}

Aebi H (1984) Catalase in vitro. Methods Enzymol 105:121-126 Ahanger MA, Qin C, Maodong Q, Dong XX, Ahmad P, Abd-Allah EF, Zhang L (2019) Spermine application alleviates salinity induced growth and photosynthetic inhibition in Solanum lycopersicum by modulating osmolyte and secondary metabolite accumulation and differentially regulating antioxidant metabolism. Plant Physiol Biochem 144:1-13

Ahlawat S, Saxena P, Ali A, Khan S, Abdin MZ (2017) Comparative study of withanolide production and the related transcriptional responses of biosynthetic genes in fungi elicited cell suspension culture of Withania somnifera in shake flask and bioreactor. Plant Physiol Biochem 114:19-28

Akhter MS, Noreen S, Mahmood S, Ashraf M, Alsahli AA, Ahmad P (2021) Influence of salinity stress on PSII in barley (Hordeum vulgare L.) genotypes, probed by chlorophyll-a fluorescence. J King Saud Univ Sci 33(1):101239

Alyemeni MN, Ahanger MA, Wijaya L, Alam P, Bhardwaj R, Ahmad P (2018) Selenium mitigates cadmium-induced oxidative stress in tomato (Solanum lycopersicum L.) plants by modulating chlorophyll fluorescence, osmolyte accumulation, and antioxidant system. Protoplasma 255(2):459-469

Bali S, Jamwal VL, Kohli SK et al (2019) Jasmonic acid application triggers detoxification of lead $(\mathrm{Pb})$ toxicity in tomato through the modifications of secondary metabolites and gene expression. Chemosphere 235:734-748

Ban Y, Honda C, Hatsuyama Y, Igarashi M, Bessho H, Moriguchi T (2007) Isolation and functional analysis of a MYB transcription factor gene that is a key regulator for the development of red coloration in apple skin. Plant Cell Physiol 48(7):958-970

Barnes PW, Williamson CE, Lucas RM et al (2019) Ozone depletion, ultraviolet radiation, climate change and prospects for a sustainable future. Nat Sustain 2(7):569-579

Bates LS, Waldren RP, Teare ID (1973) Rapid determination of free proline for water-stress studies. Plant Soil 39:205-207

Beauchamp C, Fridovich I (1971) Superoxide dismutase: improved assays and an assay applicable to acrylamide gels. Ann Biochem 44:276-287

Bulchandani N, Shekhawat GS (2020) Salicylic acid mediated up regulation of carvone biosynthesis during growth phase in cell suspension cultures of Anethum graveolens. Biotech 10(11):1-11

Cantarello C, Volpe V, Azzolin C, Bertea C (2005) Modulation of enzyme activities and expression of genes related to primary and secondary metabolism in response to UV-B stress in cucumber (Cucumis sativus L.). J Plant Interact 1(3):151-161

Cechin I, Corniani N, de Fátima FT, Cataneo AC (2008) Ultraviolet-B and water stress effects on growth, gas exchange and oxidative stress in sunflower plants. Radiat Environ Biophys 47(3):405-413

Chaurasiya ND, Uniyal GC, Lal P, Misra L, Sangwan NS, Tuli R, Sangwan RS (2008) Analysis of withanolides in root and leaf of Withania somnifera by HPLC with photodiode array and evaporative light scattering detection. Phytochem Anal 19(2):148-154

Chen GX, Asada K (1989) Ascorbate peroxidase in tea leaves: occurrence of two isozymes and the differences in their enzymatic and molecular properties. Plant Cell Physiol 30:987-998

Choi BY, Roh KS (2003) UV-B radiation affects chlorophyll and activation of rubisco by rubisco activase in Canavalia ensiformis L. leaves. J Plant Biol 46(2):117

Choudhary KK, Agrawal SB (2015) Effect of elevated ultraviolet-B on four tropical soybean cultivars: quantitative and qualitative aspects with special emphasis on gas exchange, chlorophyll fluorescence, biomass and yield. Acta Physiol Plant 37(2):31

Dhir R, Shekhawat GS, Alam A (2014) Improved protocol for somatic embryogenesis and calcium alginate encapsulation in Anethum graveolens L.: a medicinal herb. Appl Biochem Biotechnol 173(8):2267-2278

Dotto M, Gómez MS, Soto MS, Casati P (2018) UV-B radiation delays flowering time through changes in the PRC2 complex activity and miR156 levels in Arabidopsis thaliana. Plant Cell Environ 41(6):1394-1406

Escobar-Bravo R, Chen G, Kim HK, Grosser K, van Dam NM, Leiss KA, Klinkhamer P (2019) Ultraviolet radiation exposure time and intensity modulate tomato resistance to herbivory through 
activation of jasmonic acid signaling. J Exp Bot 70(1):315-327. https://doi.org/10.1093/jxb/ery347

Ghasemi S, Kumleh HH, Kordrostami M (2019) Changes in the expression of some genes involved in the biosynthesis of secondary metabolites in Cuminum cyminum L. under UV stress. Protoplasma 256(1):279-290

Gil M, Pontin M, Berli F, Bottini R, Piccoli P (2012) Metabolism of terpenes in the response of grape (Vitis vinifera $\mathrm{L}$.) leaf tissues to UV-B radiation. Phytochemistry 77:89-98

Gill SS, Tuteja N (2010) Reactive oxygen species and antioxidant machinery in abiotic stress tolerance in crop plants. Plant Physiol Bioch 48(12):909-930

Guo J, Han W, Wang M (2008) Ultraviolet and environmental stresses involved in the induction and regulation of anthocyanin biosynthesis: a review. Afr J Biotechnol 7(25):92

Heath RL, Packer L (1968) Photoperoxidation in isolated chloroplasts: I. Kinetics and stoichiometry of fatty acid peroxidation. Arch Biochem Biophys 125:189-198

Herndon JM, Hoisington RD, Whiteside M (2018) Deadly ultraviolet UV-C and UV-B penetration to Earth's surface: human and environmental health implications. J Geog Environ Earth Sci Intn 14(2):1-11

Hollósy F (2002) Effects of ultraviolet radiation on plant cells. Micron 33(2):179-197

Huarancca Reyes T, Scartazza A, Castagna A et al (2018) Physiological effects of short acute UV-B treatments in Chenopodium quinoa Willd. Sci Rep 8:371. https://doi.org/10.1038/s41598017-18710-2

Imeh U, Khokhar S (2002) Distribution of conjugated and free phenols in fruits: antioxidant activity and cultivar variations. J Agric Food Chem 50:6301-6306

Inostroza-Blancheteau C, Acevedo P, Loyola R, Arce-Johnson P, Alberdi M, Reyes-Díaz M (2016) Short-term UV-B radiation affects photosynthetic performance and antioxidant gene expression in highbush blueberry leaves. Plant Physiol Biochem 107:301-309

Jabeen M, Akram NA, Ashraf M, Alyemeni MN, Ahmad P (2020) Thiamin stimulates growth and secondary metabolites in turnip (Brassica rapa L.) leaf and root under drought stress. Physiol Plant 2:19. https://doi.org/10.1111/ppl.13215

Jaiswal D, Pandey A, Mukherjee A, Agrawal M, Agrawal SB (2020) Alterations in growth, antioxidative defense and medicinally important compounds of Curcuma caesia Roxb. under elevated ultraviolet-B radiation. Environ Exp Bot 177:104152

Jansen MA, Greenberg BM, Edelman M, Mattoo AK, Gaba V (1996) Accelerated degradation of the D2 protein of photosystem II under ultraviolet radiation. Photochem Photobiol 63(6):814-817

Khator K, Mahawar L, Shekhawat GS (2020) NaCl induced oxidative stress in legume crops of Indian Thar Desert: an insight in the cytoprotective role of HO1, NO and antioxidants. Physiol Mol Biol Plants 26(1):51-62

Khator K, Shekhawat GS (2019) Nitric oxide improved salt stress tolerance by osmolyte accumulation and activation of antioxidant defense system in seedling of $B$. juncea (L.) Czern. Vegetos 32(4):583-592

Kondo N, Kawashima M (2000) Enhancement of the tolerance to oxidative stress in cucumber (Cucumis sativus L.) seedlings by UV-B irradiation: possible involvement of phenolic compounds and antioxidative enzymes. J Plant Res 113(3):311-317

León-Chan RG, López-Meyer M, Osuna-Enciso T, Sañudo-Barajas JA, Heredia JB, León-Félix J (2017) Low temperature and ultraviolet-B radiation affect chlorophyll content and induce the accumulation of UV-B-absorbing and antioxidant compounds in bell pepper (Capsicum annuum) plants. Environ Exp Bot 139:143-151
Li FR, Peng SL, Chen BM, Hou YP (2010) A meta-analysis of the responses of woody and herbaceous plants to elevated ultraviolet-B radiation. Acta Oecol 36(1):1-9

Li Y, Fan J, Ma H, Shen F, Zhang G, Wang J et al (2011) Elevated level of polysaccharides in a high-level UV-B tolerant cell line of Bupleurum scorzonerifolium Willd. Afr J Biotechnol 10(29):5578-5586

Li Y, Qin W, Fu X, Zhang Y, Hassani D et al (2021) Transcriptomic analysis reveals the parallel transcriptional regulation of UV-Binduced artemisinin and flavonoid accumulation in Artemisia annua L. Plant Physiol Biochem 163:189-200

Liu H, Cao X, Liu X et al (2017) UV-B irradiation differentially regulates terpene synthases and terpene content of peach. Plant Cell Environ 40(10):2261-2275

Ma X, Ou Y, Gao Y et al (2016) Moderate salt treatment alleviates ultraviolet-B radiation caused impairment in poplar plants. Sci Rep 6:32890. https://doi.org/10.1038/srep32890

Mancinelli AL, Yang CH, Lindquist P, Anderson OR, Rabino I (1975) Photocontrol of Anthocyanin synthesis: III. The action of streptomycin on the synthesis of chlorophyll and anthocyanin. Plant Physiol 55:251-257. https://doi.org/10.1104/pp.55.2.251

Mariz-Ponte N, Mendes RJ, Sario S, Ferreira de Oliveira JMP, Melo $P$, Santos C (2018) Tomato plants use non-enzymatic antioxidant pathways to cope with moderate UV-A/B irradiation: a contribution to the use of UV-A/B in horticulture. J Plant Physiol 221:32-42. https://doi.org/10.1016/j.jplph.2017.11.013

Mathur S, Shekhawat GS (2013) Establishment and characterization of Stevia rebaudiana (Bertoni) cell suspension culture: an in vitro approach for production of stevioside. Acta Physiol Plant 35(3):931-939

Maurya DK, Sharma D (2020) Evaluation of traditional ayurvedic Kadha for prevention and management of the novel Coronavirus (SARS-CoV-2) using in silico approach. J Biomol Struct Dyn. https://doi.org/10.1080/07391102.2020.1852119

Mosadegh H, Trivellini A, Ferrante A, Lucchesini M, Vernieri P, Mensuali A (2018) Applications of UV-B lighting to enhance phenolic accumulation of sweet basil. Sci Hortic 229:107-116

Neale RE, Barnes PW, Robson TM et al (2021) Environmental effects of stratospheric ozone depletion, UV radiation, and interactions with climate change: UNEP environmental effects assessment panel, update 2020. Photochem Photobiol Sci 20(1):1-67

Pandey N, Pandey-Rai S (2014a) Short term UV-B radiationmediated transcriptional responses and altered secondary metabolism of in vitro propagated plantlets of Artemisia annua L. Plant Cell Tissue and Organ Cult (PCTOC) 116(3):371-385

Pandey N, Pandey-Rai S (2014b) Modulations of physiological responses and possible involvement of defense-related secondary metabolites in acclimation of Artemisia аппиа L. against shortterm UV-B radiation. Planta 240:611-627

Parihar P, Singh S, Singh R, Singh VP, Prasad SM (2015) Changing scenario in plant UV-B research: UV-B from a generic stressor to a specific regulator. $\mathrm{J}$ Photochem Photobiol $\mathrm{B}$ Bio 153:334-343

Piccini C, Cai G, Dias MC, Romi M, Longo R, Cantini C (2020) UV$B$ radiation affects photosynthesis-related processes of two Italian Olea europaea (L.) varieties differently. Plants 9(12): 1712

Porra RJ, Thompson WA, Kriedemann PE (1989) Determination of accurate extinction coefficients and simultaneous equations for assaying chlorophylls $\mathrm{a}$ and $\mathrm{b}$ extracted with four different solvents: verification of the concentration of chlorophyll standards by atomic absorption spectroscopy. Biochim Biophys Acta Bioenerg 975:384-394

Prasad SM, Srivastava G, Mishra V, Dwivedi R, Zeeshan M (2005) Active oxygen species generation, oxidative damage and 
antioxidative defense system in Pisum sativum exposed to UV-B irradiation. Physiol Mol Biol Plants 11(2):303

Rai R, Meena RP, Smita SS, Shukla A, Rai SK, Pandey-Rai S (2011) UV-B and UV-C pre-treatments induce physiological changes and artemisinin biosynthesis in Artemisia аппиа L.-an antimalarial plant. J Photochem Photobiol B Bio 105(3):216-225

Ravindran KC, Indrajith A, Pratheesh PV, Sanjiviraja K, Balakrishnan V (2010) Effect of ultraviolet-B radiation on biochemical and antioxidant defense system in Indigofera tinctoria $\mathrm{L}$. seedlings. Int J Eng Sci Technol 2:226-232

Şahin G (2019) Effects of salicylic acid and heat acclimation on thermotolerance and withanolide accumulation under high temperature stress in the cape gooseberry (Physalis peruviana L.). Turk J Bot 43(4):468-474

Salama HM, Al Watban AA, Al-Fughom AT (2011) Effect of ultraviolet radiation on chlorophyll, carotenoid, protein and proline contents of some annual desert plants. Saudi J Biol Sci 18(1):79-86. https://doi.org/10.1016/j.sjbs.2010.10.002

Schaedle M, Bassham JA (1977) Chloroplast glutathione reductase. Plant Physiol 59:1011-1012

Schreiner M, Mewis I, Huyskens-Keil S, Jansen MAK, Zrenner R, Winkler JB et al (2012) UV-B-induced secondary plant metabolites-potential benefits for plant and human health. Crit Rev Plant Sci 31(3):229-240

Sharma A, Shahzad B, Rehman A, Bhardwaj R, Landi M, Zheng B (2019) Response of phenylpropanoid pathway and the role of polyphenols in plants under abiotic stress. Molecules 24(13):2452

Shen J, Jiang C, Yan Y, Liu B, Zu C (2017) Effect of increased UV-B radiation on carotenoid accumulation and total antioxidant capacity in tobacco (Nicotiana tabacum L.) leaves. Genet Mol Res 16(1): 1492

Singh R, Mishra A, Dhawan SS, Shirke PA, Gupta MM, Sharma A (2015) Physiological performance, secondary metabolite and expression profiling of genes associated with drought tolerance in Withania somnifera. Protoplasma 252(6):1439-1450

Steyn WJ, Wand SJE, Holcroft DM, Jacobs G (2002) Anthocyanins in vegetative tissues: a proposed unified function in photoprotection. New Phytol 155(3):349-361

Suchar VA, Robberecht R (2015) Integration and scaling of UV-B radiation effects on plants: from DNA to leaf. Ecol Evol 5(13):2544-2555

Szilárd A, Sass L, Deák Z, Vass I (2007) The sensitivity of photosystem II to damage by UV-B radiation depends on the oxidation state of the water-splitting complex. Biochim Biophys Acta Bioenergetics 1767(6):876-882

Sztatelman O, Grzyb J, Gabryś H, Banaś AK (2015) The effect of UV-B on Arabidopsis leaves depends on light conditions after treatment. BMC Plant Biol 15:281. https://doi.org/10.1186/ s12870-015-0667-2

Takshak S, Agrawal SB (2014a) Effect of ultraviolet-B radiation on biomass production, lipid peroxidation, reactive oxygen species, and antioxidants in Withania somnifera. Biol Plant 58(2):328-334
Takshak S, Agrawal SB (2014b) Secondary metabolites and phenylpropanoid pathway enzymes as influenced under supplemental ultraviolet-B radiation in Withania somnifera Dunal, an indigenous medicinal plant. J Photochem Photobiol B Bio 140:332-343

Takshak S, Agrawal SB (2015) Defence strategies adopted by the medicinal plant Coleus forskohlii against supplemental ultraviolet-B radiation: augmentation of secondary metabolites and antioxidants. Plant Physiol Biochem 97:124-138

Takshak S, Agrawal SB (2018) Interactive effects of supplemental ultraviolet-B radiation and indole-3-acetic acid on Coleus forskohlii Briq.: alterations in morphological-, physiological-, and biochemical characteristics and essential oil content. Ecotoxicol Environ Saf 147:313-326. https://doi.org/10.1016/j. ecoenv.2017.08.059

Takshak S, Agrawal SB (2019) Defense potential of secondary metabolites in medicinal plants under UV-B stress. J Photochem Photobiol B Bio 193:51-88

Tripathi D, Rai KK, Rai SK, Rai SP (2018) An improved thin cell layer culture system for efficient clonal propagation and in vitro withanolide production in a medicinal plant Withania coagulans Dunal. Ind Crop Prod 119:172-182

Wu Q, Su N, Zhang X et al (2016) Hydrogen peroxide, nitric oxide and UV RESISTANCE LOCUS8 interact to mediate UV-Binduced anthocyanin biosynthesis in radish sprouts. Sci Rep 6:29164. https://doi.org/10.1038/srep29164

Yadav A, Singh D, Lingwan M, Yadukrishnan P, Masakapalli SK, Datta S (2020) Light signaling and UV-B-mediated plant growth regulation. J Integr Plant Biol 62(9):1270-1292

Yan F, Liu Y, Sheng H, Wang Y, Kang H, Zeng J (2016) Salicylic acid and nitric oxide increase photosynthesis and antioxidant defense in wheat under UV-B stress. Biol Plant 60(4):686-694

Yokawa K, Kagenishi T, Baluška F (2016) UV-B induced generation of reactive oxygen species promotes formation of BFA-induced compartments in cells of Arabidopsis root apices. Front Plant Sci 6:1162

Yu GH, Li W, Yuan ZY, Cui HY et al (2013) The effects of enhanced UV-B radiation on photosynthetic and biochemical activities in super-high-yield hybrid rice Liangyoupeijiu at the reproductive stage. Photosynthetica 51(1):33-44

Zhang X, Ding X, Ji Y, Wang S et al (2018) Measurement of metabolite variations and analysis of related gene expression in Chinese liquorice (Glycyrrhiza uralensis) plants under UV-B irradiation. Sci Rep 8(1):1-17

Zlatev ZS, Lidon FJ, Kaimakanova M (2012) Plant physiological responses to UV-B radiation. Emir J Food Agric 9:481-501

Zvezdanović J, Cvetić T, Veljović-Jovanović S, Marković D (2009) Chlorophyll bleaching by UV-irradiation in vitro and in situ: Absorption and fluorescence studies. Radiat Phys Chem $78(1): 25-32$

Publisher's Note Springer Nature remains neutral with regard to jurisdictional claims in published maps and institutional affiliations. 